\title{
Manzano, V. (2017). La era de la juventud en Argentina. Cultura, politica y sexualidad desde Perón hasta Videla. Buenos Aires, Ar- gentina: Fondo de Cultura Económica. 447 pp.
}

Florencia Gandara ${ }^{1}$

Desde hace más de una década, la historiadora Valeria Manzano se dedica al estudio de la juventud en Argentina. La era de la juventud es la traducción al español de su tesis doctoral defendida en la Universidad de Indiana. En este libro la autora se propone investigar el proceso por el cual la juventud se configuró como una categoría cultural y política excepcionalmente relevante en la Argentina de las décadas de 1950 y 1970. Para hacerlo estudia tanto a los propios jóvenes como actores -explorando sus intereses, acciones y decisiones cultuales, políticas y sexuales- como así también los modos en que la juventud fue representada por distintos sectores de la sociedad que, como la autora señala, no sólo la representó sino que también, en distintas ocasiones, se propuso eliminarla física y simbólicamente. En relación con ello, Manzano aborda particularmente la (conflictiva) relación de la juventud con las nociones de autoridad y las jerarquías existentes en la sociedad argentina de esos años. Asimismo, indaga en los procesos de conformación de algunas de las identidades y estereotipos de género vinculados a la juventud más potentes del siglo XX, contextualizándolos e historizándolos, lo que constituye un valor particularmente importante de La era... pues invita a pesar a la juventud atendiendo a los múltiples y complejos sentidos que incorporó durante esos treinta años de historia argentina.

El libro de Manzano se posiciona dentro de la denominada nueva historiografía de la juventud, por lo que se propone analizar el proceso de conformación de la juventud en relación a las dinámicas de los procesos de modernización sociocultural. Discutiendo con las perspectivas que entienden el desarrollo de la juventud como parte de un proceso lineal de modernización sociocultural-prefigurado, homogéneo, igual en todo el mundo-, Manzano sostiene que si se subraya lo móvil, fragmentario, heterogéneo y regionalizado de esos procesos, entonces es posible poner el foco en el carácter conflictivo, tensionado, dinámico y plural de la juventud, es decir, aquello que la caracteriza. Para llevar adelante esa tarea la autora recurre, despliega y dialoga a lo largo de todo el libro con una gran diversidad y riqueza de fuentes provenientes de archivos nacionales e internacionales tanto públicos como privados, así como también con entrevistas producidas por ella misma.

La era de la juventud en Argentina está compuesto, luego de una rigurosa introducción, por ocho capítulos a tra-

\footnotetext{
${ }^{1}$ Universidad Nacional de San Martín. Contacto: florencia.gandara@gmail.com
} 
vés de los cuales la autora hilvana temas, problemáticas y períodos de la historia argentina con vivencias, actitudes y prácticas de las personas que, a lo largo de esas décadas, conformaron la juventud. El libro finaliza con un apartado de conclusiones. El capítulo inaugural, El espacio de la juventud, está dedicado a reflexionar sobre la llegada de la juventud a la escena pública argentina. En relación con ello Manzano realiza tres operaciones: en primer lugar reflexiona sobre la cronología de la juventud en Argentina y ubica su emergencia a principios de la década de 1950 , cuando Perón realiza una serie de invocaciones a los jóvenes colocándolos como depositarios del futuro del peronismo e incita su organización como estudiantes secundarios, lo que por su parte acarrea fuertes críticas de sus principales opositores. En segundo lugar, examina el proceso por el cual fueron apareciendo actores presentados como idóneos no sólo para hablar de los jóvenes sino, fundamentalmente, para tomar decisiones sobre ellos. En este grupo íntegramente adulto- señala la presencia de psicólogos, psiquiatras, sociólogos, políticos, sacerdotes y periodistas y analiza qué representaciones hacían circular sobre los jóvenes, qué prácticas habilitaban, con qué contextos políticos se relacionaban y qué ideas de futuro implicaban. En tercer lugar, analiza las diversas experiencias de los propios jóvenes en ese contexto, sus variadas decisiones y sus propias formas de representarse. Estas tres operaciones son las que articulan el libro.

Avocándose desde aquí a temas particulares, Elmundo de los estudiantes, segundo capítulo del libro, se detiene en la vida de los estudiantes secundarios y universitarios durante las décadas de 1950 y 1960. En la cresta de la nueva ola, el tercer capítulo, se pregunta por construcción de sentidos de pertenencia generacional durante los años 60s. Superponiendo discursos oficiales a vivencias de quienes transitaban espacios educativos en estos años, Manzano señala que estos jóvenes habitaban una profunda ambivalencia: mientras por una parte encarnaban, en tanto jóveneseducados ideales de modernización, progreso y futuro, por otra parte estaban sujetos al autoritarismo enciclopédico, a estrictas reglas escolares y a estrechos márgenes de expresión. Atendiendo a un contexto fuertemente atravesado por golpes de estado, la guerra fría y la revolución cubana, analiza tanto las formas en que grupos católicos, sectores políticos y militares comenzaron a contornear y difundir la idea del «militante radicalizado»-sinónimo de «infiltración comunista»-como así también los modos en que los propios jóvenes se organizaron políticamente y/o construyeron sus sentidos de pertenencia generacional. El tercer capítulo, en relación con ello, se detiene precisamente en sus pautas de producción y consumo de música, vestimenta, formas de esparcimiento y concepciones sobre la sexualidad. El carácter contencioso de la juventud, en este punto, se yuxtapone a la mencionada ambivalencia. Tal como demuestra la autora, los jóvenes argentinos no compartían pautas de consumo, ídolos, gustos de ropa ni pretensiones: mientras se consolidaban en la escena pública también se diferenciaban, reforzaban distinciones de clase y generaban estereotipos de género vin- 
culados a la sexualidad.

En este sentido los siguientes capítulos son particularmente elocuentes, pues en ellos analiza los modos -más prácticos que reflexivos, como señala la autora- en que tanto mujeres como varones de los años '60s y principios de los '70s expresaron sus disconformidades con los autoritarismos y alianzas conservadoras reinantes y, en ése camino, fueron conformando identidades propias y, nuevamente, modelando identidades de género, estereotipos y prácticas sexuales legítimas. Ella se va de casa, el cuarto capítulo, está dedicado a las jóvenes de los años '60s. Desde la óptica de la autora, el pánico moral que existía respecto de la huida de las adolescentes de la casa familiar -una práctica no tan extendida material cuanto sí simbólicamente- expresó un espacio de pugna intergeneracional en el que se disputaban y desafiaban nociones tradicionales en defensa de nuevas prácticas y actitudes. Las jóvenes, en este sentido, vivieron, experimentaron las consecuencias y respondieron más temprano a las consecuencias de algunos de los procesos e implicancias de la modernización sociocultural que protagonizaron los jóvenes. Algunos años después, sin embargo, los jóvenes también dieron sus respuestas. Una fraternidad de varones pelilargos, el quinto capítulo, analiza la cultura rock de mediados de la década de 1960 y principios de los años '70s como un espacio privilegiado -entre otras variantes de la cultura contestataria juvenil- de sociabilidad masculina en que se disputaron sentidos de masculinidad y respetabilidad imperantes. Como Manzano señala, si bien las jóvenes reaccionaron a los mandatos patriar- cales aceptando prácticas como el sexo prematrimonial -aunque asociadas al inminente matrimonio- y los varones redefinieron criterios de masculinidad y respetabilidad, en ambos casos se sostuvo explícitamente la heterosexualidad obligatoria y, podríamos agregar, se reforzaron-aunque redefinidos- estereotipoa binarios de género.

Pero la autora va más allá porque en el sexto capítulo del libro, Cerca de la revolución, se pregunta específicamente por el proceso de involucramiento de los jóvenes en algunas de las formas de organización política más radicalizadas del momento. Al respecto, analiza y señala que la coyuntura del mayo argentino (de 1969, cuando se dan revueltas obraras y estudiantiles en varias provincias contra el gobierno militar encabezado por Onganía) fue tanto la culminación de un proceso de politización estudiantil que había comenzado a mediados de la década como así también inicio de una nueva época de la politización juvenil. En este sentido, reconstruye cómo se fortaleció una asociación (propia pero también construida por sectores adversarios) entre juventud politizada y un ideal revolucionario, y explora los vínculos entre la caracterización de Argentina como país tercermundista, la adscripción a proyectos políticos radicales y la emergencia de nuevas pautas de consumo juvenil (libros, música y turismo). Asimismo, indaga en los motivos por los cuales el peronismo fue el proyecto más popular entre los jóvenes, y se detiene a pensar su lugar en la fuerte crisis al interior del mismo. Desde su perspectiva, la novela familiar-como denomina a la crisis al interior del peronismo que disputaron 
los jóvenes organizados con «los viejos» líderes del partido- reprodujo algunas disputas intergeneracionales propias del ámbito familiar en el ámbito de la política nacional. Antes de analizar el desenlace trágico de dicha disputa, Poner el cuerpo, el séptimo capítulo del libro, explora los modos en que algunos sectores de la sociedad argentina -con distintas motivaciones- se esforzaron por disciplinar los cuerpos jóvenes mientras, al mismo tiempo, se extendía la disociación entre el sexo y el matrimonio. En ésa línea, explora minuciosamente dos estereotipos consolidados durante fines de los años '60s y principios de los '70s. Por un lado, el de mujer delgada que vestía jeans o minifaldas y debía modelar su cuerpo con dietas para ser sensual, que se instaló entre feroces debates sobre la moral que se disputaban sobre cuerpo de las mujeres. Por el otro, el del militante político ideal: fuerte, resistente e incansable, se trataba de un estereotipo de juventud masculina que también era necesariamente heterosexual y monógama. Al respecto, indaga las formas en que este segundo estereotipo-retóricamente igualitario pero cotidianamente excluyente- reguló prácticas corporales y sexuales, y condicionó tanto la presencia de mujeres en las cúpulas de estas organizaciones como sus vínculos con incipientes organizaciones feministas y de homosexuales.

Las tres operaciones con las cuales comienza el libro son retomadas en el capítulo final del libro, Los jóvenes y la «restauración de la autoridad», en el Manzano retoma el mencionado desenlace de la interna peronista y analiza el proyecto que se propuso dar marcha atrás a los cambios políticos, culturales y sexuales encabezados por los jóvenes en las décadas anteriores. En relación a la reflexión sobre los sectores que consolidaban representaciones sobre la juventud, la autora examina cómo alianzas conservadoras que se habían formado lentamente durante los años anteriores ocuparon -incluso antes de 1976cargos públicos y posiciones desde las cuales se difundieron ciertas retóricas sobre la juventud como parte de los múltiples esfuerzos para restituir la autoridad en distintos niveles de la vida cotidiana (familiar, escolar, etc.). Además, reconstruye cómo concretaron mecanismos tanto legales como ilegales de criminalización, persecución e intento de eliminación física de quienes representaban una amenaza para el matrimonio y la familia, encarnación del futuro de la patria: los jóvenes. Como señala Manzano «el rostro del enemigo interno era joven» (p.348) y por eso fueron sus cuerpos los que se encontraron además de atravesados por nuevos estereotipos- en la línea de fuego. Retomando la preocupación por las experiencias de los propios jóvenes, la autora explora cómo incluso en este contexto pervivieron ciertos espacios de resistencia, como la cultura rock y su cotidianeidad. Sobre la periodización de la era de la juventud argentina, la autora evalúa para concluir que ni la juventud ni la militancia política juvenil recuperaron, de allí en más, sus sentidos utópicos y de promesa de futuro, que fueron apagados con la vida de miles de cuerpos (jóvenes) (p. 385).

El libro aquí comentado se caracteriza tanto por la interacción y diálogo entre sus distintas secciones como también por la autonomía de cada capítulo. 
Estas características se relacionan con una cuidadosa selección de temas y modos de abordaje de la autora, que atiende al mismo tiempo a la especificidad de cada tema, a su interrelación y a su historicidad. En este sentido, este libro construye sus argumentaciones a partir de la combinación rigurosa de análisis cuanti y cualitativos. Para realizar esta tarea, Manzano recurre a una enorme multiplicidad y diversidad de fuentes provenientes de archivos públicos y privados tanto nacionales como extranjeros, así como también publicaciones gubernamentales, estadísticas educativas, publicaciones periódicas locales y extranjeras -de circulación nacional, político partidarias, juveniles, culturales y contraculturales, de psicología y pedagogía, de las fuerzas de seguridad y católicas, entre otras- memorias, películas, música y entrevistas realizadas por ella misma.

Retomando tanto su objetivo general como su posicionamiento en relación a la nueva historia de la juventud, a lo largo del libro la autora realiza un sutil y enriquecedor juego de esca- las. Recurriendo por momentos a casos particulares y por momentos a cuestiones generales, su argumentación va elaborando una trama -acaso la era de la juventud argentina- que no es ni homogénea ni lineal. Al contrario, configura una juventud que aparece como fundamentalmente contenciosa, extraordinariamente diversa en sus características, intereses, perspectivas políticas y consumos, que se esfuerza por reforzar distinciones en su interior $\mathrm{y}$, fundamentalmente, está profundamente atravesada por los procesos sociales, políticos y económicos locales.

La era de la juventud en la Argentina. Cultura, politica y sexualidad desde Perón hasta Videla, en suma, es un estudio que aporta conocimientos cardinales sobre la juventud argentina, realizando al mismo tiempo estimulantes sugerencias que invitan elaborar nuevas preguntas sobre los modos en que los jóvenes vivieron, se representaron $-y$ fueron representados- $\mathrm{y}$ tomaron decisiones tanto durante esas décadascomo en las posteriores. 